\title{
Protocol of Toothbrushing Based on Bioavailability of Fluoride in Toothpaste: A Systematic Review
}

\author{
Protocolo de Cepillado Basado en la Biodisponibilidad del Flúor en Dentífricos: \\ Una Revisión Sistemática
}

Moreno-Radic, V.* \& Sanchez Gonzalez, J.*

MORENO-RADIC, V. \& SANCHEZ GONZALEZ, J. Protocol of toothbrushing based on bioavailability of fluoride in toothpaste: a systematic review. Int. J. Odontostomat., 10(3):433-441, 2016.

ABSTRACT: The objective of the study is to propose a protocol for the appropriate use of fluorides in dentifrices (Dt), based on its bioavailability in saliva (Bs) and / or plaque (Bp) through a systematic review (SR). SR of the literature from 2005 to 2015 in PubMed, Cochrane and SciELO. Inclusion criteria: clinical studies in vivo, Spanish and English, made only with $\mathrm{Dt}$ that measured $\mathrm{Bs}$ and $\mathrm{Bp}$. The results were evaluated in relation to: 1) Concentration of fluoride in $\mathrm{Dt}$, 2) Brushing time with Dt, 3) Frequency of brushing, 4) Rinse post-brushing and 5) Amount of Dt on the brush. Twelve (12) studies were selected. 1) Bs increases $241 \%$ when using a $5000 \mathrm{ppm}$ of Dt compared to $1450 \mathrm{ppm}$. 2) Bs is increased by $55 \%$ by increasing the duration of brushing $40 \mathrm{~s}$ to $120 \mathrm{~s} 3$ ) Bp increases by $68 \%$ when brushing 3 times a day compared to 2 times. 4) Not rinsing or rinsing with $<10 \mathrm{ml}$ for $<10 \mathrm{~s}$ increases Bs to $270 \%$ compared to rinses higher volume / time. 5) By increasing the amount of Dt of $0.5 \mathrm{~g}$ to $1.5 \mathrm{~g}$, Bs increases up to $266 \%$. The use of $1.5 \mathrm{~g}$ of Dt $\geq 1450 \mathrm{ppm}$ of fluoride for $\geq 120$ $\mathrm{s}, 3$ times a day is recommended and once brushing is complete avoiding oral rinse with water or non fluoride mouthwash .

KEY WORDS: saliva, plaque, dentifrice, calculus, caries treatment, dental public health.

\section{INTRODUCTION}

Despite continuous efforts in dentistry to prevent dental caries, $17 \%$ of 2 year olds were found to have obvious dental decay affecting their primary teeth and gradually increasing to nearly $100 \%$ in the adult population according to the Ministry of Health in Chile (MINSAL 2010). There are several prevention systems available, however, the use of fluoride $(F)$ still remains the most effective caries prevention tool, with overwhelming evidence of anti-cariogenic effect.

Fis a preventive element that due to its protective action of enamel and dentin helps prevent demineralization, promotes remineralization, and reduces bacterial activity in dental plaque; but to achieve these effects constant contact with tooth structure is required. (Pacuar et al. 2007).

Among the methods of self-administration of fluoride dentifrice (Dt) is considered the most effective intervention for prevention, both for its proven clinical action as well as for its social acceptability (Marinho et al., 2003). A recent Cochrane review concluded that higher relative caries preventive effects were associated with increased Dt fluoride concentrations (Walsh et al., 2010), but the effectiveness depends on bioavailability of the active ingredient (fluorine), which may vary according to the concentration of fluoride Dt, amount, frequency and duration of brushing, and rinsing protocol post-brushing (Parnell \& O'Mullane, 2013).

By analyzing the frequency of daily brushing according to the study by Koerber et al. (2005) in children $5^{\circ}$ and $8^{\circ}$ grade, $47 \%$ brush their teeth $1-2$ times a day, $42 \%$ more than 2 times daily, and $11 \%$ less than 1 time per day, indicating that there is still a lack of knowledge or habit in relation to the frequency of daily brushing and actual preventive effect on caries lesions. About a third of the studies observed by Macgregor \& Rugg-Gunn (1985) indicated that the average brushing time was $<56 \mathrm{~s}$, while two-thirds 
reported a brushing time $\geq 56 \mathrm{~s}$ and $70 \mathrm{~s}$. The best estimate of the real time appears to vary between 30 to 60 seconds (Van der Weijden et al., 1993). As for post-brushing rinses, most people rinse with potable water as final part of the oral hygiene routine, generally practiced subconsciously (Parnell \& O'Mullane).

Currently there is no protocol for tooth brushing associated with increased bioavailability of fluoride, thereby achieving greater efficacy against the appearance of carious lesions. Therefore, the aim of this article is to conduct a systematic review of studies on bioavailability in saliva and plaque using fluoride Dt by variations of tooth brushing in order to establish a protocol for brushing greater benefits for oral hygiene.

\section{MATERIAL AND METHOD}

Type of study: Narrative review based on a systematic search of the literature on tooth brushing with fluoride dentifrice considering factors aimed at increasing the bioavailability of fluoride.

Search Date: May 2015

Studies: Clinical studies, meta-analyzes and systematic reviews.

Information sources: structured search in different sources of bibliographic information (tertiary, secondary and primary), with the following structure results:

1. Source of tertiary information (Cochrane Library Plus). Preferred Search Advanced Search, and used the following keywords Medical Subject Headings (MeSH): "fluoride concentration" or "dentifrice Saliva" and their equivalents in Spanish. 2. Sources of secondary information (PubMed and SciELO): (MeSH) "fluoride" or "fluorides" and "toothpaste" or "toothpastes" and "attention" or "concentration". "Fluorides" or "fluoride" and "dentifrices" or "dentifrice" and "salivary" and "level". "Salivary" and "fluorides" or "fluoride" and "level" and their equivalents in Spanish.

3. Sources of primary information: review of relevant in each of the items selected in the previous literature search.

Screening and Selection criteria: The inclusion and exclusion criteria are shown in detail in Table I.

Step 1: Titles and abstracts were reviewed by 2 authors (VM. and J.S.) and selected for further review if they met the inclusion criteria (304 potential eligible articles), considering the selection criteria established, reviewed and excluded articles that did not reach the minimum quality threshold for its design according to the Spanish version "Critical Appraisal Skills Program" (CASPe).

Step 2: Abstracts were independently reviewed by 2 authors (VM. and J.S.) and selected per their consensus according to the same inclusion criteria used in step 1. If consensus was not reached, the abstract was set aside for further evaluation.

Step 3: Full-text articles of abstracts selected in step 2 were retrieved and reviewed by 1 author (V.M.). Inclusion was based on the consensus between 2 investigators (VM. and J.S). The reference lists of all articles selected in step 3 were reviewed, and the full texts of potentially interesting studies were examined.

Data Extraction. Data extraction was conducted independently by 2 reviewers (V.M and J.S) using a data extraction form.

Table I. Inclusion and Exclusion Criteria.

\section{Inclusion criteria}

Studies using only Dentifrices, with measurement of fluoride concentration in plaque and saliva.

- Spanish and English.

- Studies in humans.

- Articles and reviews published between 2005 - 2015.

\section{Exclusion criteria}

- Exclude measurements made using other fluoride sources as tablets, rinses, solutions, etc.

- Exclude studies in languages other than English or Spanish.

- Exclude studies conducted over 10 years ago. 
The information extracted from each article is shown in detail in Table II. In brief, these included authors, country, years of study, sample size, number of participant, and grouped according to study variable 1) Concentration of fluoride in Dt, 2) time brushing with $\mathrm{Dt}, 3$ ) frequency of brushing, 4) Rinse postbrushing and 5) amount of dt on the brush.

\section{RESULTS}

In total, 304 study reports were identified from database searches. Only 25 articles were eligible for full-text retrieval. Of these, 13 articles were excluded for the reasons presented in the flow diagram (Fig. 1). Table II shows scientific articles selected for the systematic review, classified according to the variables studied.

The studies analyzed were conducted in the following countries: United States, Sweden, England, the Netherlands (Amsterdam), India and Brazil.

The articles were longitudinal observational experimental studies.
The sample size of the studies was highly variable, ranging from 12 to 51 participants, with a range comprising between 4 and 65 years.

\section{Concentration Dt regarding Bp and Bs.}

Five scientific articles analyzed this variable, within which different concentrations of fluoride in Dt were used.

Creeth et al. (2013) compared fluoride concentrations of $250 \mathrm{ppm}$ with $1150 \mathrm{ppm}$, noting that Bs increase 5,13 times by using Dt of $1150 \mathrm{ppm}$ vs $250 \mathrm{ppm}$.

Nordstrom et al., evaluated fluoride concentrations of $1450 \mathrm{ppm}$ and $5000 \mathrm{ppm}$, where Bs increased 3,14 times, while the Bp achieved an increase of $37 \%$ using concentration of $5000 \mathrm{ppm}$ compared to $1450 \mathrm{ppm}$. The same concentrations were used by Nordström \& Birkhed (2013), finding a $59 \%$ increase in Bp. Although lower fluoride concentrations were used, similar results were found in the Nagpal \& Damle (2007) report. Finally, Campos et al., (2015) points out that there is only an increase in Bs after brushing teeth with Dt, but also that there is a decrease divided into two phases: the first phase occurs a rapid decline of fluoride present in the mouth in first 10 minutes, and then a second phase of gradual decline,

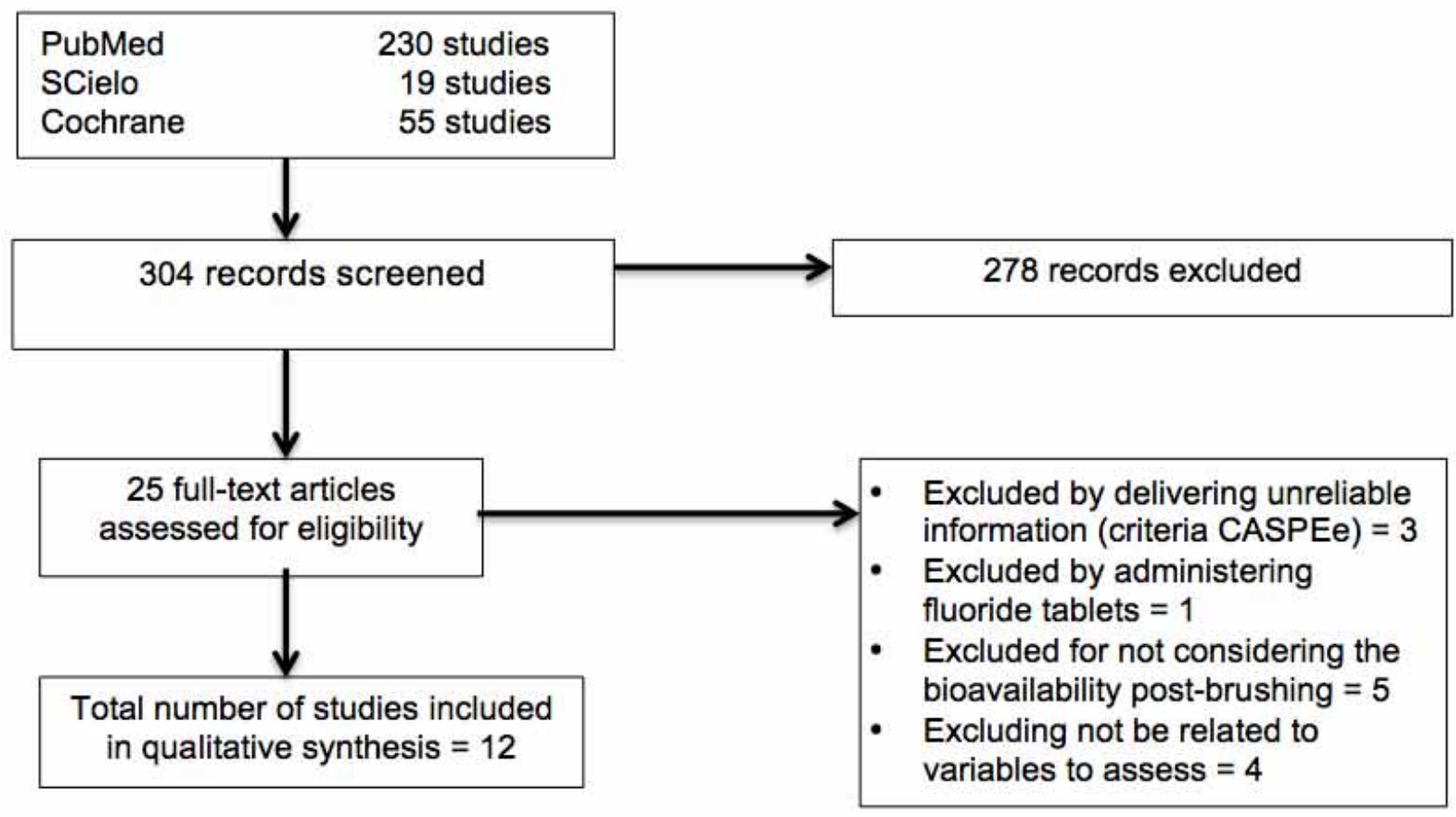

Fig. 1 Flow Diagram of systematic review of the literature. 
MORENO-RADIC, V. \& SANCHEZ GONZALEZ, J. Protocol of toothbrushing based on bioavailability of fluoride in toothpaste: a systematic review. Int. J. Odontostomat., 10(3):433-441, 2016

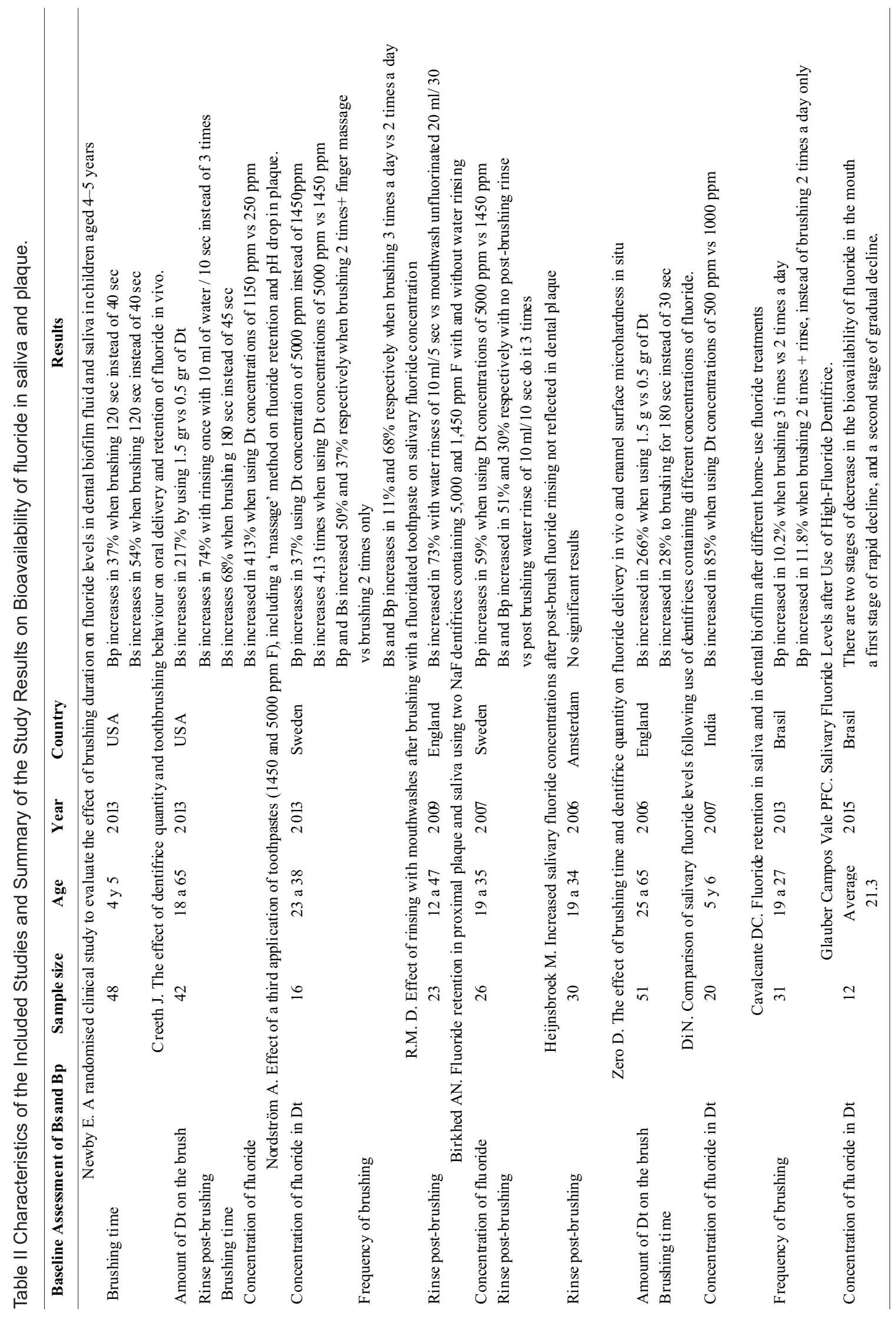


which is attributed to a union of fluoride to oral surfaces, which must first dissociate into a free solution before disposal.

All results show a direct positive relationship between the concentration of fluoride in Dt and bioavailability of fluoride in saliva and plaque.

Brushing time in relation to Bioavailability in saliva and / or Bp. Three scientific articles analyzed this variable, considering different brushing times (30, 45 , 60,120 and 180 seconds).

Newby et al. (2013), found that brushing for 120 s bioavailability increases by $56 \%$ and $3 \%$, respectively in saliva and plaque, compared to $40 \mathrm{~s}$ brushings. Moreover, in the study by Zero et al. (2010) the Bs increase by $28 \%$ when brushing 180 seconds compared to 30 seconds. Finally Creeth et al. finding that Bs increases by $47 \%$ when brushing for 120 seconds instead of 30 seconds and an increase in Bs $68.7 \%$ compared brushing 180 seconds instead of 45 seconds.

All authors conclude that there is a direct positive relationship between increased brushing time and increased Bs and Bp.

Frequency of brushing in relation to $B$ and $B p$. Two scientific articles analyzed this variable, comparing brushing with Dt twice a day against brushing twice a day plus a third fluoride exposure, either by Dt-brush, Dt oral massage using the finger or fluoride mouthwash.

Nordström \& Birkhed found an increase of $50 \%$ and $37 \%$ in $\mathrm{Bp}$ and $\mathrm{Bs}$ respectively by using two brushings a day with Dt plus a third exposure by oral Dt-massage using the finger, compared to only brushing with Dt twice a day. Furthermore brushing the teeth three times daily the Bp and Bs increased 68 $\%$ and $11 \%$ respectively, compared with brushing twice a day. Similar results are found in the report by Souza et al. (2014) where Bp increases $10.2 \%$ when brushing with Dt three times a day versus twice a day; and Bp increases $11.8 \%$ when brushing twice a day plus a third exposure of fluoride with fluoride mouthwash, compared with two daily brushings.

Both articles conclude that there is a direct positive relationship between the administration of fluoride (Dt-brush, oral Dt-massage using the finger, mouth rinse) and increased Bp-Bs, regardless of how it is performed.
Rinse post brushing relative to $\mathrm{Bs}$ and $\mathrm{Bp}$. Four articles analyzing the presence or absence of post brushing rinse relative to $\mathrm{Bs}$ and $\mathrm{Bp}$, also including other variables: liquid used (water, fluoride mouth rinse, non fluoridated mouthwash), amount of liquid and rinse time.

Heijnsbroek et al. (2006), conducted different protocols post brushing rinse; (1) 30 second rinse with $10 \mathrm{ml}$ of water; (2) spit out excess toothpaste without rinsing; (3) 30 second rinse with $10 \mathrm{ml}$ of fluoridated mouthwash. The results were not significant.

(Nordström \& Birkhed) observed that Bs and Bp increases $51 \%$ and $30 \%$ respectively when excess of Dt is spit, compared to rinsed for 10 seconds with $10 \mathrm{ml}$ of water repeating this process 3 times.

Creeth et al. compares performing post brushing rinse once to doing it three times. Rinses were made for 10 seconds with $10 \mathrm{ml}$ of water. An increase of $74 \%$ in Bs was found when rinsing once compared to repeating it 3 times.

Bs is higher while the post brushing rinse is performed for periods of less than 5 seconds and $10 \mathrm{ml}$ volumes according to the results obtained by Duckworth et al. (2009).

According to the authors, the increased bioavailability of fluoride in the mouth in plaque and saliva is achieved when excess of Dt is spit out without rinsing, followed by rinsing post brushing with volumes less than $10 \mathrm{ml}$, for less than 5 seconds time and if possible with fluoridated mouthwash repeating this process once.

Amount of $\mathrm{Dt}$ on the brush in relation to $\mathrm{Bp}$ and Bs. Two scientific articles analyzed the relation between amount of Dt and Bs, which used $0.5 \mathrm{~g}$ and $1.5 \mathrm{~g}$ of fluoridated Dt.

Creeth et al., found that Bs increase by $217 \%$ when brushing with $1.5 \mathrm{~g}$ of Dt compared with $0.5 \mathrm{~g} \mathrm{Si}$ milar data is mentioned in the study of Zero et al. where Bs increases by $266 \%$ when using $1.5 \mathrm{~g}$ compared to $0.5 \mathrm{~g}$

No scientific articles that measured and analyzed Bp were found.

According the data mentioned above, there is a direct positive relationship between the amount of $D t$ and $\mathrm{Bs}$, but it is unknown whether this pattern is similar in Bp. 


\section{DISCUSSION}

There is currently an interest in implementing different strategies of motivation and education in the population in order to reduce and prevent oral disease.

Based on the strategies related to dental hygiene it has been seen that there are different manageable variables in brushing technique. All these variables attempt to modify the substantivity of fluoride in the mouth, because of fluoride is available in saliva with concentrations greater than $100 \mathrm{ppm}$ can react with the calcium of the tooth surface and plate adhered to the tooth to form calcium fluoride, acting finally as a reservoir of fluoride that can dissolve and release the ion involved in remineralization and demineralization of the caries process (MINSAL, 2010).

Currently the protocols of daily brushing recommend a duration of 2 minutes, 2 times a day with toothpaste fluoride $1450 \mathrm{ppm}$, which would be the most massive traded concentration (Colgate), but does not take into account the amount of toothpaste used, post brushing rinse, or the actual effectiveness by increasing the concentration of fluoride in the toothpaste.

In this SR, regarding the relationship between the concentration of fluoride in $\mathrm{Dt}$ and $\mathrm{Bs}-\mathrm{Bp}$, despite that different studies generated variations in the time of brushing, amount of Dt used and embodiment of rinse post brushing, there was always an increase in fluoride concentration found in saliva and plaque, by increasing the concentration of fluoride in Dt.

By increasing about 5 times the concentration of fluoride in Dt of $250 \mathrm{ppm}$ to $1150 \mathrm{ppm}$, the concentration of fluoride in saliva was $80 \%$ higher. It could be useful for tooth brushing protocol in children with teeth still in formation, where the recommended fluoride concentrations are expected not to exceed $1100 \mathrm{ppm}$ in order to prevent fluorosis (Walsh et al.).

Nordstrom (Nordstrom et al., 2013) used fluoride concentrations 1450 and 5000 ppm and similar results were obtained. Regarding measurements in plate, thebioavailability of fluoride was increased $37 \%$.

While initial fluoride concentrations were higher in saliva than those obtained in plate it is important to consider that this increase has low substantivity in time, due to self-cleaning that is continuously generated in the mouth with food, liquids and the same salivary glands secretion, this gain tends to drop within a few hours, whereas in the plate, this substantivity usually remains in a constant state due to its ability to act as a reservoir of fluoride.

Therefore, within the tooth brushing protocol using Dt 1450 ppm must be considered for patients with low cariogenic risk and higher concentrations of $2500 \mathrm{ppm}$ or $5000 \mathrm{ppm}$ for patients with high risk of decay or patients with difficulty to carry out proper hygiene.

Regarding the positive relationship between brushing time and $\mathrm{Bp}-\mathrm{Bs}$, authors indicated that it is due to the amount of Dt retained between the bristles of the toothbrush post brushing, since about $30 \%$ is deposited on the brush with brushing 30 seconds while a 3 minute brushing retained only $10 \%$. Therefore the least $D t$ remains deposited on the brush, the greater the distribution of $\mathrm{Dt}$ into the oral cavity.

It is necessary to note that 3 minutes of brushing is often not a duration that can be carried out routinely by most patients because it is considered a very long duration. In a brushing of 2 minutes, despite the low bioavailability compared to 3 minutes, there is a gain in the Bs of $47 \%$ versus a 45 seconds brush, so it can be recommended (Creeth et al.).

Regarding the relationship between the frequency of brushing and Bs-Bp, all authors (Nordström \& Birkhed; Souza et al.) agree that the there is a direct positive association between a third dose of fluoride mouth and Bs $-\mathrm{Bp}$, either with a toothbrush or a finger massage using Dt.

According to the results obtained by Nordstrom et al. (2013), higher bioavailability saliva is obtained by performing brushing 2 times plus finger massage with Dt compared to 3 times brushings, possibly because the Dt does not remain within the bristles of the toothbrush, but rather is deposited completely within the oral cavity. Nonetheless based on the results obtained in plaque, the difference is not significant, and it could be that this reservoir of fluoride appears to have a saturation level regarding the acquisition of fluoride.

In Souza et al. study measurements of fluoride bioavailability were performed 8 hours after the addition of fluorine, either post-brushing or the use of mouthwash. The results showed that a third brushing or a third incorporation of fluorine by mouthwash, could generate a greater protective benefit, especially as the 
results obtained in plaque, since in saliva as presenting a constant salivary clearance results are insignificant. This point is important to consider in a remineralizing or preventive therapy for caries lesions because often people do not have a toothbrush and a finger massage using Dt could suffice to acquire the protective effects.

Thus, different types of hygiene can be proposed to adapt to the capabilities of each patient in order to achieve a similar protective effect. Therefore, a third brushing, mouthwash or toothpaste using finger massage is beneficial for incorporating fluorine.

Regarding post-brushing rinse in relation to Bs$\mathrm{Bp}$, fluoride levels in mouth change between different patients according to the post brushing rinse protocol being performed, being able to affect the bioavailability positively or negatively.

The study by Heijsbroek et al. (2006), compares different post brushing rinse protocols; (1) rinsed for 30 seconds with $10 \mathrm{ml}$ of water; (2) without rinsing; (3) rinsed for 30 seconds with $10 \mathrm{ml}$ of fluorinated mouthwash. The results of bioavailability in saliva showed no significant differences. This can be explained by the fact that fluoride in the mouth measurements where taken 6 hours after brushing, having a salivary clearance during this time.

In the remaining three studies (Nordström \& Birkhed; Duckworth et al.; Creeth et al.) a direct association between not performing post-brushing, rinsing or rinsing with fluoride mouthwash and increased bioavailability of fluoride in saliva and plaque was found.

Most studies conclude that it is more beneficial to perform a rinse once with water with volumes $<10$ $\mathrm{ml}$ for short periods not exceeding 10 seconds. Performing a rinse is desired and should be used preferably with concentrations greater than $225 \mathrm{ppm}$. Nevertheless higher concentrations of fluoride in the mouth are obtained by avoiding post-brushing rinse, but it should be considered that many patients do not feel comfortable maintaining the remaining toothpaste and have the need to remove it with a mouth rinse. This increase of bioavailability could have negative effects due to the toxicity of fluoride, specifically in Dt of high concentrations as $5000 \mathrm{ppm}$, because $5 \%$ to $10 \%$ of Dt could be ingested during tooth brushing, especially when avoiding post brushing water rinse (Sjögren \& Birkhed, 1994).
Nevertheless these Dt are recommended for high-risk patients, such as patients with active caries lesions, orthodontic treatment, motor or neurological disabilities, hyposalivation, radiation, and consumption of drugs that alter salivary flow, etc.

For this reason it is important to assess the actual effect of post brushing rinse-off because it might increase the bioavailability of fluoride, resembling the concentrations obtained by using high concentration Dt.

Regarding the amount of Dt during tooth brushing, all authors found a direct positive association to increase the amount of $\mathrm{Dt}$ in relation to Bs-Bp.

This increase in Bs can be up 3.66 times higher when using Dt of $1.5 \mathrm{~g}$ vs $0.5 \mathrm{~g}$, therefore it would seem to have a true protective effect.

Although measurements with higher amounts to $1.5 \mathrm{~g}$ of fluorinated Dt were not performed, any amount higher than this is thought not to necessarily have a beneficial effect, possibly because any excess will be eliminated eventually at time of expectoration.

It would be interesting to consider for future research, the effects of active agents such as calcium citrate or sodium trimetaphosphate on the bioavailability of fluoride, and how these could be considered in the protocol of oral hygiene, since tooth surface fluoride concentration increases faster when using $\mathrm{AmF}$ vs $\mathrm{NaF}$.

Although the main strength is the design of the study, a SR based on CASPEe standards ensuring systematic work, we must also consider some limitations. Study limitations are conditioned mainly by the quality and heterogeneity of the studies, therefore it is not possible to reach a consensus but it is possible to compare the different results.

\section{CONCLUSION}

A more specific oral hygiene protocol is proposed for the patients in order to achieve a higher anti cariogenic effect.

Thus after the collection of information available in the electronic database it can relate the bioavailability of fluoride with toothbrushing, considering that the most important factor is the concentration of fluoride, followed 
by amount of Dt used, post brushing rinse protocol and finally brushing time.

Therefore the proposed protocol considers; (1) concentrations of fluoride $\mathrm{Dt} \geq 1450 \mathrm{ppm}$, (2) duration of brushing of 2 minutes or more, (3) brushing frequency 3 times a day or incorporating a third administration of fluoride with mouthwashes fluorinated or Dt without using brush, (4) amount of Dt of $1.5 \mathrm{~g}$, (5) avoiding oral rinse with water post-brushing, or doing it with mouthwash or water but with $10 \mathrm{ml}$ for 5 seconds and only once.

MORENO-RADIC, V. \& SANCHEZ GONZALEZ, J.Protocolo de cepillado basado en la biodisponibilidad del flúor en dentífricos: una revisión sistemática. Int. J. Odontostomat., 10(3):433-441, 2016.

RESUMEN: El objetivo de este studio es proponer un protocolo para el uso adecuado de fluoruros en dentífri$\cos (\mathrm{Dt})$, basado en su biodisponibilidad en saliva (Bs) y/o placa (Bp) mediante una revisión sistemática (RS). RS de la literatura 2005- 2015 en PubMed, Cochrane y SciELO. Criterios de inclusión: estudios clínicos in vivo, español e inglés, realizados únicamente con Dt que midieran Bs y Bp. Los resultados fueron evaluados en relación a: 1) Concentración de flúor en el Dt, 2) Tiempo de cepillado con Dt, 3) Frecuencia de cepillado, 4) Enjuague post-cepillado y 5) Cantidad de Dt en el cepillo. Fueron seleccionados 12 estudios. 1) La Bs aumenta en un $241 \%$ al utilizar un Dt de 5000 ppm en comparación con un 1450 ppm. 2) Bs aumenta en un $55 \%$ al aumentar la duración del cepillado de 40 s a 120 $\mathrm{s}$, 3) La Bp aumenta en un $68 \%$ al cepillarse 3 veces al día en comparación a 2 veces. 4) No enjuagarse o enjuagues $\mathrm{de}<10 \mathrm{ml}$ por $<10 \mathrm{~s}$ puede aumentar la Bs hasta en un 270 $\%$ en comparación a enjuagues con mayor volumen/tiempo. 5) Al aumentar la cantidad de Dt de $0,5 \mathrm{~g}$ a $1,5 \mathrm{~g}$, la Bs aumenta hasta en un $266 \%$. Se recomienda utilizar $1,5 \mathrm{~g}$ de Dt $\geq 1450$ ppm de flúor por $\geq 120 \mathrm{~s}, 3$ veces al día, y evitar enjuague oral con agua o colutorios sin flúor una vez finalizado el cepillado.

PALABRAS CLAVE: saliva, plaqua, dentifricos, calculo, tratamiento caries, salud dental public.

\section{REFERENCES}

Souza, D. C. C.; Maltz, M. \& Hashizume, L. N. Fluoride retention in saliva and in dental biofilm after different home-use fluoride treatments. Braz. Oral Res., 28(1):15, 2014.
Creeth, J.; Zero, D.; Mau, M.; Bosma, M. L. \& Butler, A. The effect of dentifrice quantity and toothbrushing behaviour on oral delivery and retention of fluoride in vivo. Int. Dent. J., 63 Suppl., 2:14-24, 2013.

Duckworth, R. M.; Maguire, A.; Omid, N.; Steen, I. N.; McCracken, G. I. \& Zohoori, F. V. Effect of rinsing with mouthwashes after brushing with a fluoridated toothpaste on salivary fluoride concentration. Caries Res., 43(5):3916, 2009.

Heijnsbroek, M.; Gerardu, V. A.; Buijs, M.J.; van Loveren, C.; ten Cate, J. M.; Timmerman, M. F. \& van der Weijden, G. A. Increased salivary fluoride concentrations after postbrush fluoride rinsing not reflected in dental plaque. Caries Res., 40(5):444-8, 2006.

Koerber, A.; Burns, J. L.; Berbaum, M.; Punwani, I.; Levy, S.R.; Cowell, J.; Flay, B. Toothbrushing Patterns over time in at-risk metropolitan african-american 5th- 8th graders: A brief communication. J. Public Health Dent., 65(4):240-3, 2005.

Macgregor, I. D. \& Rugg-Gunn, A. J. Toothbrushing duration in 60 uninstructed young adults. Community Dent. Oral Epidemiol., 13(3):121-2, 1985.

Marinho, V. C.; Higgins, J. P.; Sheiham, A. \& Logan, S. Fluoride toothpastes for preventing dental caries in children and adolescents. Cochrane Database Syst. Rev., (1):CD002278, 2003.

Ministerio de Salud (MINSAL). Web Site. Santiago, Ministerio de Salud de Chile, 2010. Diponible en: www.minsal.cl

Nagpal, D. I. \& Damle, S. G. Comparison of salivary fluoride levels following use of dentifrices containing different concentrations of fluoride. J. Indian Soc. Pedod. Prev. Dent., 25(1):20-2. 2007.

Newby, E. E.; Martinez-Mier, E .A.; Zero, D.T.; Kelly, S. A.; Fleming, N.; North, M.; Bosma, M.L. A randomised clinical study to evaluate the effect of brushing duration on fluoride levels in dental biofilm fluid and saliva in children aged 4-5 years. Int. Dent. J., 63 Suppl. 2:39-47, 2013.

Nordström, A. \& Birkhed, D. Effect of a third application of toothpastes (1450 and $5000 \mathrm{ppm} \mathrm{F}$ ), including a 'massage' method on fluoride retention and $\mathrm{pH}$ drop in plaque. Acta Odontol. Scand., 71(1):50-6, 2013.

Parnell, C. \& O'Mullane, D. After-brush rinsing protocols, frequency of toothpaste use: fluoride and other active ingredients. Monogr. Oral Sci., 23:140-53, 2013.

Páucar, A. M. A. Uso de agentes quimioterapéuticos para el control y regresión de pacientes preadolecentes. Cybertesis. Respositorio de Tesis Digitales, 2007. 
Sjögren, K. \& Birkhed, D, Effect of various post-brushing activities on salivary fluoride concentration after toothbrushing with a sodium fluoride dentifrice. Caries Res., 28(2):127-31, 1994.

Vale, G. C.; Cruz, P. F.; Bohn, A. C. C. E. \& deMoura, M. S. Salivary fluoride levels after use of high-fluoride dentifrice. Scientific World J., 2015:302717, 2015.

Van der Weijden, G. A.; Timmerman, M. F.; Nijboer, A.; Lie, M.A. \& Van der Velden, U. A comparative study of electric toothbrushes for the effectiveness of plaque removal in relation to toothbrushing duration. Timerstudy. J. Clin. Periodontol., 20(7):476-81, 1993.

Walsh, T.; Worthington, H. V.; Glenny, A. M.; Appelbe, P.; Marinho, V. C. C. \& Shi, C. Comparación entre pastas dentales fluoradas de diferentes concentraciones para prevenir la caries dental en niños y adolescentes. Biblioteca Cochrane Plus, (1), 2010. Disponible en: http:/ /www.cochrane.org/es/CD007868/comparacion-entrepastas-dentales-fluoradas-de-diferentes-concentraciones-para-prevenir-la-caries

Zero, D.; Creeth, J. E.; Bosma, M. L.; Butler, A.; Guibert, R. G.; Karwal, R.; Lynch, R. J.; Martinez-Mier, E. A.; González-Cabezas, C. \& Kelly, S. A. The effect of brushing time and dentifrice quantity on fluoride delivery in vivo and enamel surface microhardness in situ. Caries Res., 44(2):90-100, 2010.
Correspondence to:

Jenny Sánchez González

Universidad del Desarrollo

Faculty of Medicine

School of Dentistry.

Avenida Vicuña Mackenna 9630

CL 7610658

La Florida

Santiago

CHILE

Email: drajennysanchez@gmail.com

Received: 20-06-2016

Accepted: 11-10-2016 